\title{
Long Haired Mini Dachshund
}

National Cancer Institute

\section{Source}

National Cancer Institute. Long Haired Mini Dachshund. NCI Thesaurus. Code C53900.

The Long Haired Mini Dachshund is a long-haired variety of dachshund with a height up to 5 inches. 